\title{
Compression of Satellite Imagery Sequences Using Wavelet for Detection of Natural Disaster
}

\author{
Albertus Joko Santoso ${ }^{1}$, Findra Kartika Sari Dewi ${ }^{2}$ and Thomas Adi Purnomo Sidhi ${ }^{3}$ \\ Informatics Engineering, University of Atma Jaya Yogyakarta \\ Jl. Babarsari 43, Yogyakarta 55281, Indonesia \\ albjoko@staff.uajy.ac.id,findra@staff.uajy.ac.id,th.adi.ps@staff.uajy.ac.id
}

\begin{abstract}
Indonesia, geographically and geologically, is potentially encounter natural disasters. One of the tools used to early detect disaster is sensor of ocean waves change, but it has drawbacks including the time difference between information/warnings obtained with the disaster event is very short, less than 30 minutes. The faster detector is required, so the time difference will be longer. For example, early detection of natural disasters information system, which can be made with the pattern recognition of satellite imagery sequences of before and during natural disaster images.

This study was conducted to determine the right wavelet to compress the satellite image sequences. The compressed images will be used to perform the pattern recognition of natural disaster using artificial neural network. This study use satellite imagery sequences of tornadoes and hurricanes. The eight wavelets used are Haar, Coiflet 1, Coiflet 3, Symlet 2, Symlet 5, 1 AJS, AJS 2, and AJS 3. The test results are then compared with the compression ratio.

Result of this study are the comparison of wavelet used to compress satellite imagery sequences, which is save the storage space, access time, processing time and delivery time.
\end{abstract}

Keywords: wavelet, image compression, satellite imagery

\section{Introduction}

Computer technology, both hardware and software, is growing very fast. The development of the Internet and multimedia technologies are growing exponentially, resulting in the huge amount of data managed by the computer (Tan, 2001). In addition, the use of digital images is growing rapidly. It leads to serious problems in the storage and delivery of image data. Although storage technology has progressed significantly in this time, but the transmission capacity has not (Gonzalez and Woods, 2008). Image data management needs to consider the storage capacity and transmission bandwidth (Talukder and Hirada, 2007). The implications of image data which consume a lot of space is the length of time to process the data. In the computer world, file compression can be used to shorten the data processing time.

Indonesia, geographically and geologically, is potentially encounter natural disasters. Efforts to prevent or early detection continues to be studied in order to produce fast and accurate predictions. One of the efforts that have been done is the installation of a sensor which can detect the changes of ocean waves, that is placed in the middle of the ocean. However, the sensor has drawbacks, such as the time difference between the information obtained with the occurrence of natural disasters is very short, probably 
less than 30 minutes. Hence, a detector which can provide information at least 24 hours in advance, so people can evacuate themselves long before a natural disaster occurs.

This study use 24 bit-colored satellite imagery sequences of tornadoes and hurricanes, with $512 \times 512$ pixels of size. The eight wavelets used are Haar, Coiflet 1 , Coiflet 3, Symlet 2, Symlet 5, 1 AJS, AJS 2, and AJS 3. Those wavelets are used to compress the satellite imagery sequences. The test results are then compared with the compression ratio.

\section{Literature Review}

\subsection{Image Compression Using Wavelet}

At this time the use of computers in efforts to achieve the resolution required for multimedia applications or large image databases will have limitations. This is due to the increasing amount of digital images, as well as the size of an image are getting bigger. To overcome this, compression process is necessary [6].

The larger the image size, the more memory is needed. However, most images contain duplicate data, where a pixel has the same intensity with neighboring pixels, so each pixel wasted storage space. An image contains a lot of same parts (regions), so these same sections do not need to be coded repeatedly as wasteful or redundant. Image compression reduces the redundancy of the image data stored or transmitted only, and then can be reconstructed in accordance with human visual perception [9].

One technique for image data compression is using wavelet transformation. In image compression, the wavelet transformation has the advantage that a very small difference between the original image and the reconstruction image, even after quantization process. The non-negative threshold value will make the image elements that have a very small value can be zeroed, so it can produce a very sparse matrix [8]. The existence of sparse matrix is useful when an image data will be stored or transmitted, in addition to the results of the reconstruction would have a very small value of MSE or as good as the original image when seen visually by the human eye.

At this time, wavelet applications were received much attention in the world of research; one of the usages is for image analysis. As analytical techniques of two-dimensional discrete signals, such as images, wavelet decomposese signals into signals mean, details of vertical, horizontal and diagonal at some desired levels. In other words, wavelet decomposes the original signal into signals in several frequencies (called multi-resolution analysis). Analysis can be performed by Discrete Wavelet Transform [5] or the standard decomposition techniques and the non-standard with Haar wavelet [2]. Image signature generated by wavelet is taken from wavelet coefficient at a certain level (e.g., 3, 4 or 5) and can be sized much smaller than the original.

\subsection{Artificial Neural Network}

Artificial Neural Network (ANN) is a network of a group of small processing unit modeled based on human neural network. ANN is an adaptive system that can change its structure to solve problems based on external or internal information that flows through the network. Simply put, ANN is a non-linear statistical modeling tool. ANN can be used to model complex relationships between inputs and outputs for finding patterns in the data. ANN concept originated on the paper of McCulloch and Pitts (1943) that attempts to formulate a mathematical model of brain cells. 
According to Haykin [4], a neural network is a parallel-distributed processor and has tendency to keep knowledge acquired from experience and keep it available for use. It resembles the brain works in two things: 1 . Knowledge acquired by the network through a learning process. 2. Strength of the relationship between nerve cells, known as synaptic weights, is used to store knowledge.

ANN has a very good ability to perform various pattern recognition processes. Pattern recognition that is often done by applying $\mathrm{ANN}$ is the problem of image pattern recognition.

\section{Research Methods}

\subsection{Research Materials}

Test images used as research material are satellite imagery sequences. While satellite imagery sequence is a series of still images displayed in sequence, so that give the impression to the eyes as a moving image. The test images used for this study are two types of movement sequences of satellite imagery, the tornadoes and storms, which were then tested with Haar, Coiflet 1, Coiflet 3, Symlet 2, Symlet 5, 1 AJS, AJS 2, and AJS 3.
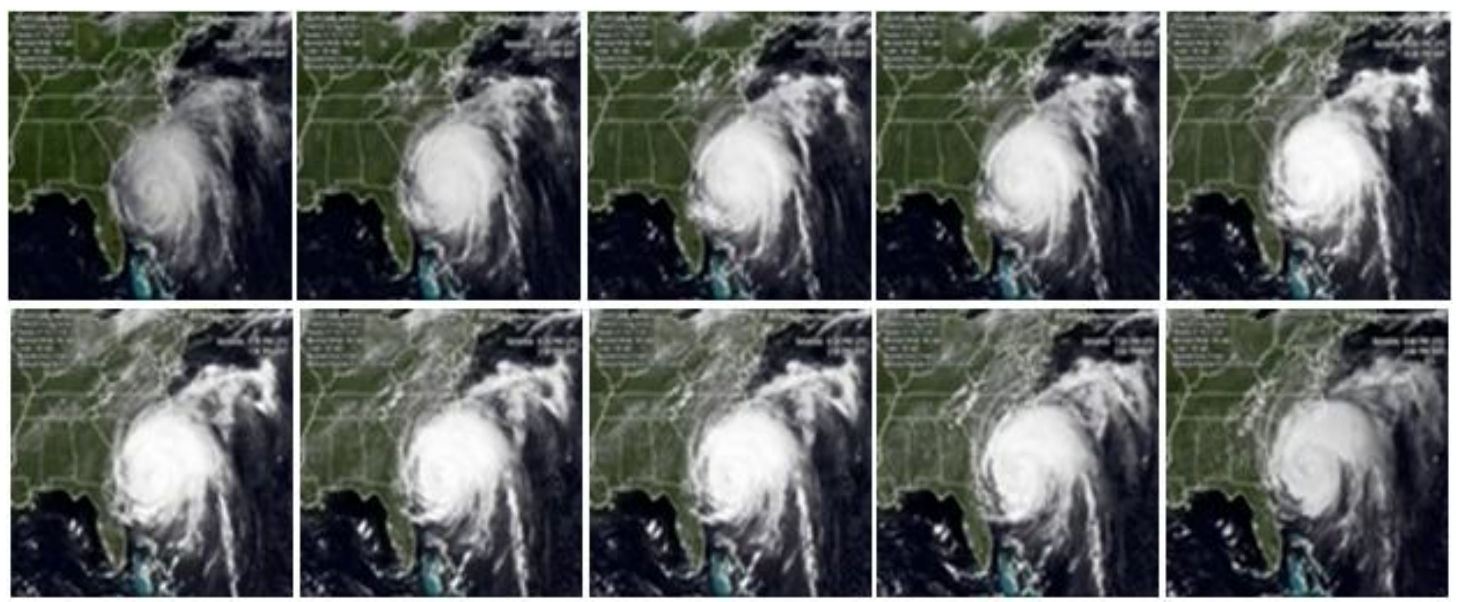

Figure 1. Example of Satellite Imagery

The study materials obtained through various search sites. The data obtained in the form of video will be convert into images by capturing each frame in the video. Once the images are taken then the image processing begins with choosing images that will be processed.

\subsection{Research Tools}

Minimum equipment used in this study is a computer with specs of Intel core duo processor $1.66 \mathrm{GHz}, 667 \mathrm{MHz}$ FSB, $2 \mathrm{MB}$ L2 cache, 80 GB $5400 \mathrm{rpm}$ HDD, 1 GB DDR. Windows operating system comes with the program package of Matlab 7 and other supporting applications such as video processing to convert video into images and visualization of calculation results.

\subsection{Research Process}

3.3.1. Details of Research Process: This study is done by performing these following steps:

1. Preparation of videos and images needed. 
2. Processing the data to fit the data to be used in image processing.

3. Designing and building program for the compression of satellite imagery sequences using wavelet.

4. Testing the eight selected wavelet to the percentage of compression ratio on satellite imagery sequences.

5. Processing of satellite imagery sequences with wavelet transformation, resulting multiresolution of the original image. Wavelet is used because the transformation has the ability to bring out special features on the test images. The wavelet transformation is useful as a feature extraction method and also for reducing the dimension of the input images. As the input basis of artificial neural network, used some sizes of vector images, which is $16 \times 16$, $32 \times 32$ and $64 \times 64$, and then compared its effect on recognition performance.
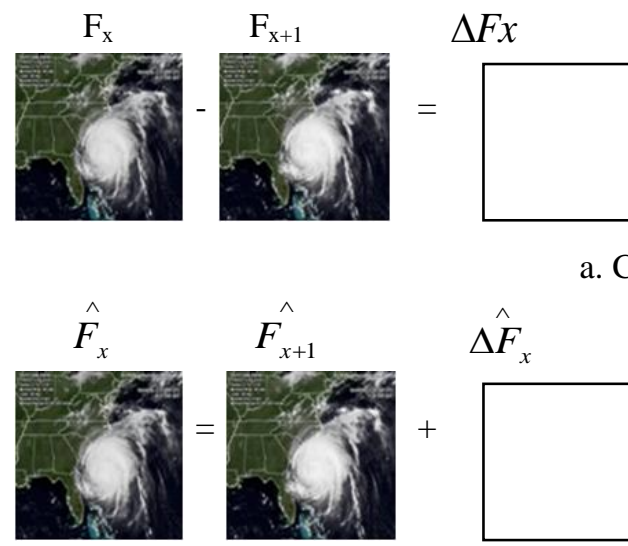

a. Compression Process

b. Decompression Process

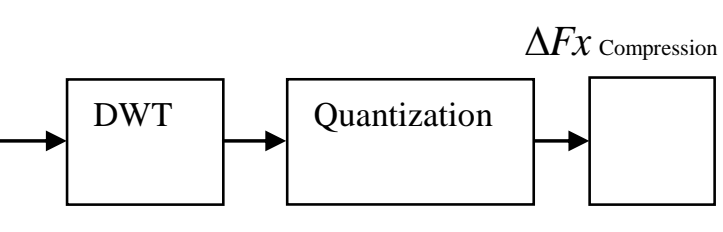

$\Delta F x_{\text {Compression }}$
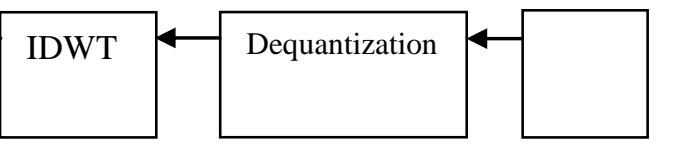

Figure 2. Compression Process of Satellite Imagery

\section{Result and Discussion}

\subsection{Compression of Satellite Imagery Sequences Using Selected Wavelet}

In this study has done some inter-frame compression testing for satellite imagery sequences to PSNR and compression ratio. Satellite imagery sequences used consisted of two types of disasters, i.e. tornadoes and hurricanes. Each type of natural disaster represented by 10 satellite imagery sequences with a size of $512 \times 512$ pixels. The eight wavelets used are Haar, Coiflet 1, Coiflet 3, Symlet 2, Symlet 5, 1 AJS, AJS 2, and AJS 3. The testing program of satellite imagery sequences compression using selected wavelets are as follows:

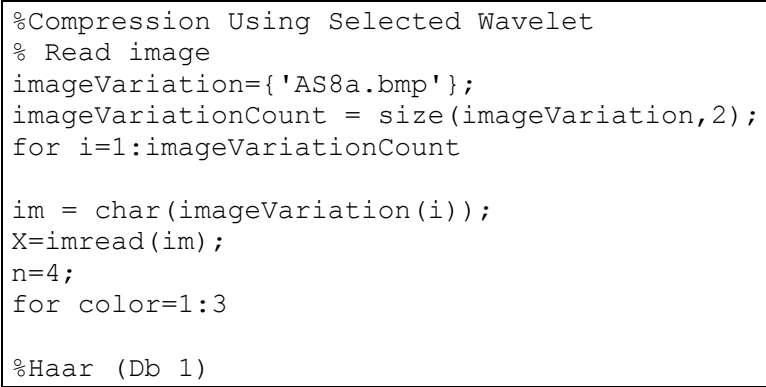




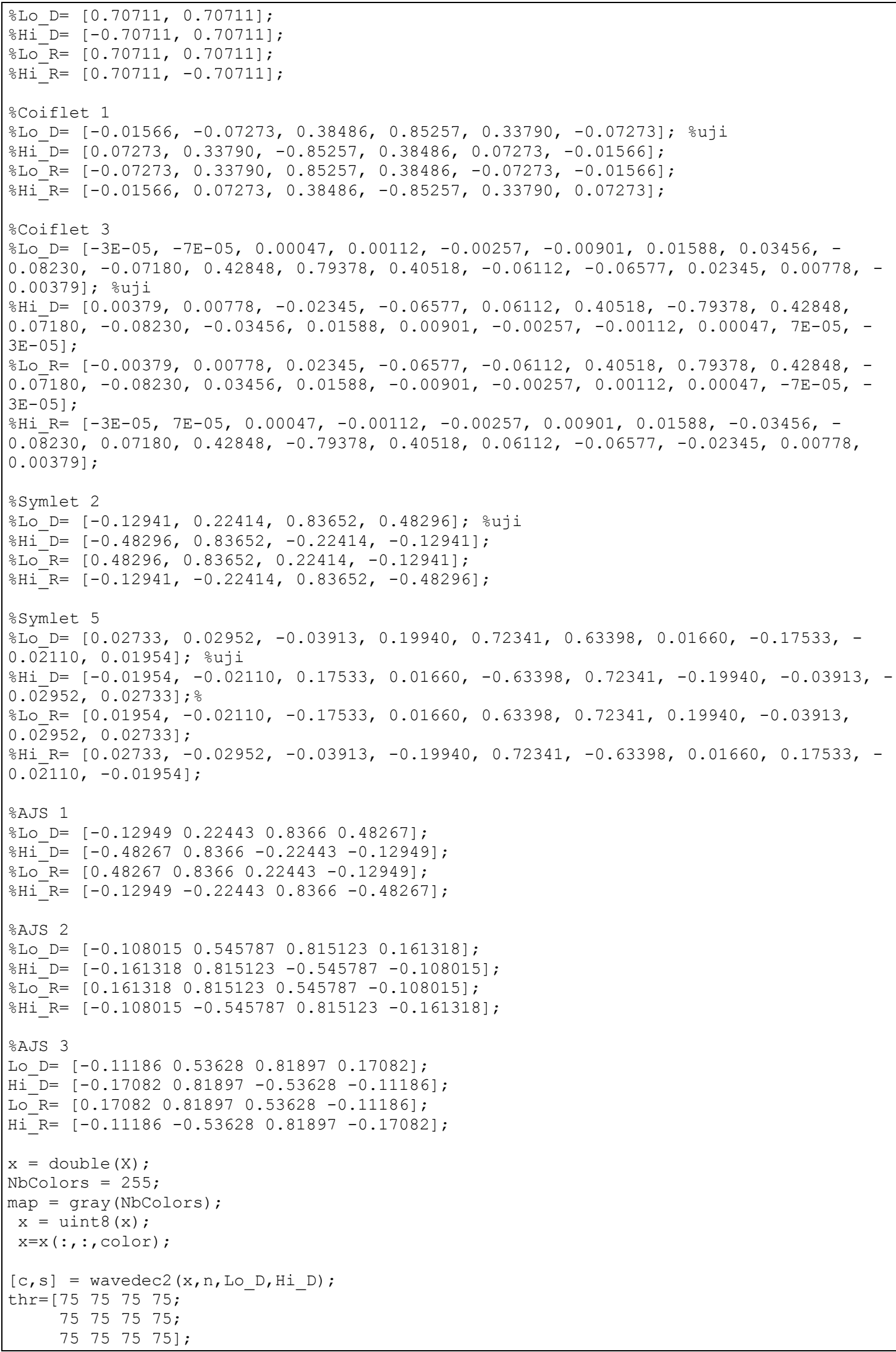




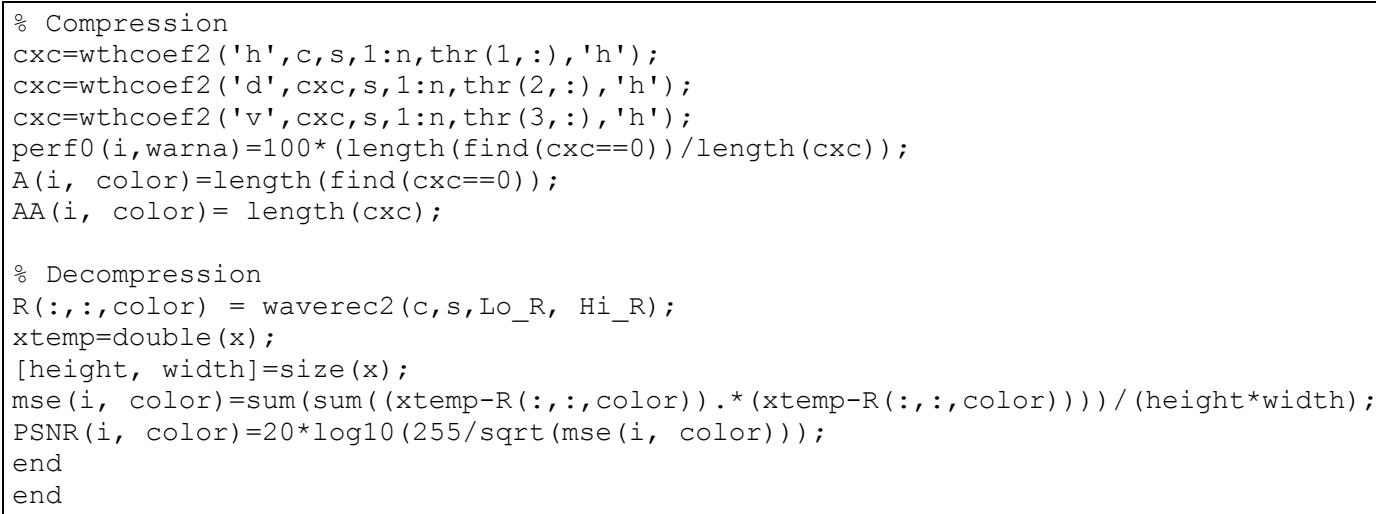

\subsection{Testing of Selected Wavelets to Compression Ratio}

Based on Table 1 and Figure 3, for tornado image sequences appears that the wavelet which produces the highest compression ratio is Haar then followed by Symlet 2 and AJS 1. Haar has the highest compression ratio because it has the least amount of filter length, which is 2, while the Symlet 2 and AJS 1 have filter length of 4 . As on Table 2 and Figure 4, for the hurricane image sequences seemed that the wavelets which produce the highest compression ratio are Symlet 2 and AJS 1.

Table 1. Comparison of Selected Wavelets to Compression Ratio (Tornado)

\begin{tabular}{cll}
\hline No & Wavelet & Compression Ratio (\%) \\
\hline 1 & Haar & 99.26233 \\
\hline 2 & Coiflet 1 & 99.16833 \\
\hline 3 & Coiflet 3 & 98.826 \\
\hline 4 & Symlet 2 & 99.229 \\
\hline 5 & Symlet 5 & 99.058 \\
\hline 6 & AJS 1 & 99.22867 \\
\hline 7 & AJS 2 & 99.20567 \\
\hline 8 & AJS 3 & 99.20567 \\
\hline
\end{tabular}

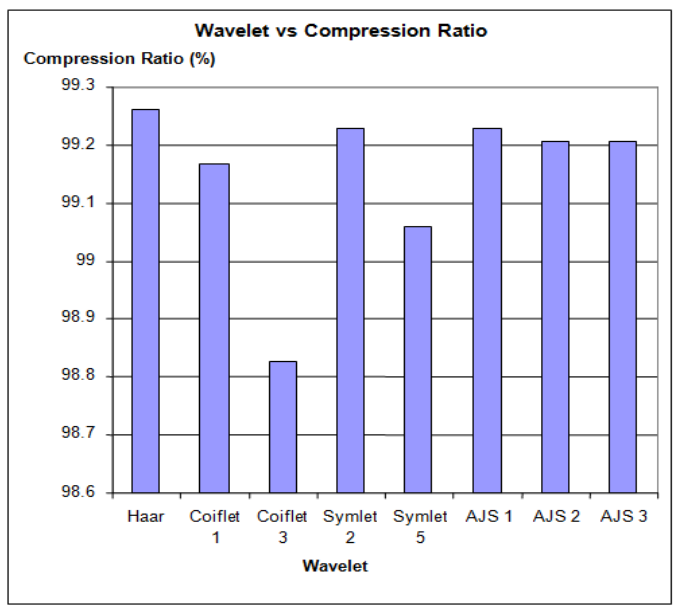

Figure 3. Comparisons of Selected Wavelets to Compression Ratio (Tornado) 
Table 2. Comparison of Selected Wavelets to Compression Ratio (Hurricane)

\begin{tabular}{cll}
\hline No & Wavelet & Compression Ratio (\%) \\
\hline 1 & Haar & 98.38333 \\
\hline 2 & Coiflet 1 & 98.34967 \\
\hline 3 & Coiflet 3 & 98.068 \\
\hline 4 & Symlet 2 & 98.43867 \\
\hline 5 & Symlet 5 & 98.30767 \\
\hline 6 & AJS 1 & 98.43833 \\
\hline 7 & AJS 2 & 98.21867 \\
\hline 8 & AJS 3 & 98.22333 \\
\hline
\end{tabular}

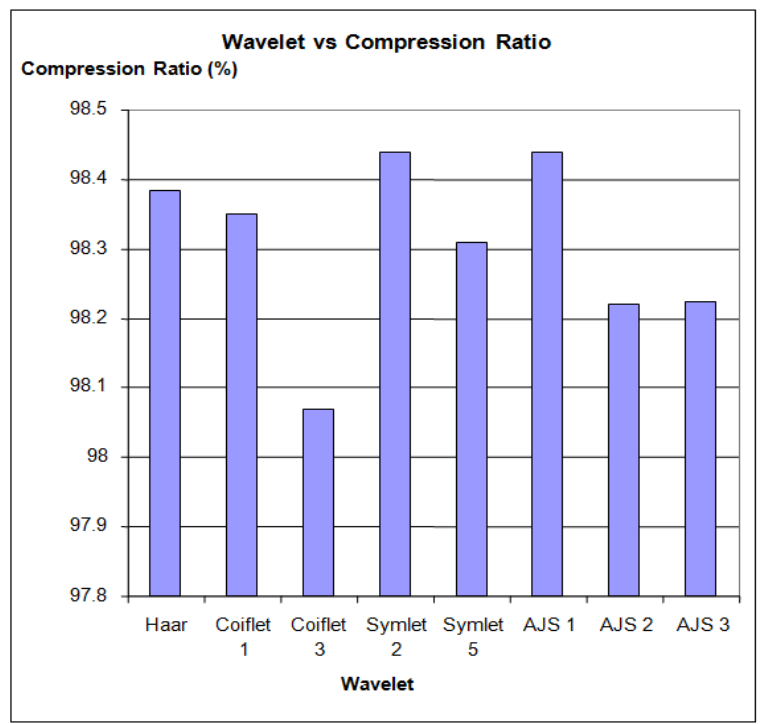

Figure 4. Comparisons of Selected Wavelets to Compression Ratio (Hurricane)

\section{Conclusion}

Based on the test results and discussion, the conclusion of this research is: Three wavelets that produce high compression-ratio of satellite imagery sequences respectively are Haar, Symlet 2 and AJS 1.

\section{Future Works}

From the results of this study, the compressed images will be compared with PSNR (Peak Signal to Noise Ratio), and then perform the pattern recognition of natural disaster using artificial neural network. Further, the works can be continued on the implementation of information system for detection of natural disaster.

\section{References}

[1] Arymurthy, A. Murni and S. Setiawan, "Pengantar Pengolahan Citra”, PT. Elex Media Komputindo, Jakarta, (1992).

[2] K. Chakrabarti, M. Garofalakis, R. Rastogi and K. Shim, "Approximate Query Processing Using Wavelet”, Proceedings of 26th International Conference on Very Large Data Bases, (2000) September 10-14; Cairo, Egypt. 
[3] R. O. Duda, P. E. Hart, D. G. Stork, "Pattern Classification (2nd Edition)", Wiley, New York, (2001).

[4] S. Haykin, "Neural Networks: A Comprehensive Foundation", Macmillan, NY, (1994).

[5] S. Mallat, "A Wavelet Tour Of Signal Processing", Second Edition, Academic Press, USA (1999).

[6] M. B. Pardo and C. T. Reijden, "Embedded Lossy Image Compression Based on Wavelet Transform", Proceedings of the 4th EURASIP - IEEE Region 8 International Symposium on Video/Image Processing and Multimedia Communications on VIPromCom, (2002) June 16-19; Zadar, Croatia.

[7] J. Schuermann, "Pattern Classification: A Unified View of Statistical and Neural Approaches", Wiley\&Sons, New York, (1996).

[8] C. Schremmer, "Empirical Evaluation of Boundary Policies for Wavelet-Based Image Coding", Technical Report TR 7-2001, Department for Mathematics and computer Science, University Mannheim, Germany, (2001).

[9] S. N. Sivanandam, A. P. Pandian, P. Rani, “The Internet and Management”, vol. 17, no. 2, (2009).

\section{Authors}

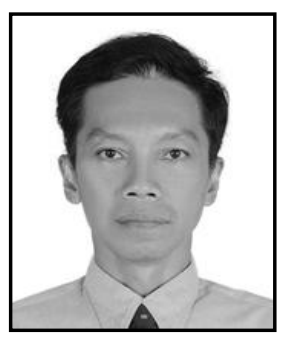

\section{Albertus Joko Santoso}

Born in Yogyakarta. His bachelor degree is in Electrical Engineering from Gajah Mada University. He graduated from his master degree majoring Electrical Engineering, Gajah Mada University, Yogyakarta. His doctoral degree got from Gajah Mada University, focusing on Wavelet for Pattern Recognition.

He has been lecturing in Atma Jaya Yogyakarta University for more than 15 years. His current research interest is in pattern recognition and data mining. Some of his publications are Compression Ratio And Peak Signal To Noise Ratio in Grayscale Image Compression Using Wavelet published in International Journal of Advanced Science and Technology (IJAST) 2011, Color Image Compression Using Orthogonal Wavelet Viewed From Decomposition Level and Peak Signal To Noise Ratio published in International Journal of Computer Science and Technology 2011, and Intraframe Compression on Sequential Image Using Wavelet in International Journal of Computer Science and Technology 2011.

Dr. Ir. Albertus Joko Santoso, MT actively in Center Study for Energy, Yogyakarta, Indonesia. He is a member of Computer Science Teacher Association. He is granted for the best paper in Information System Seminar (SESINDO) in 2011. He has a hobby in reading and biking.

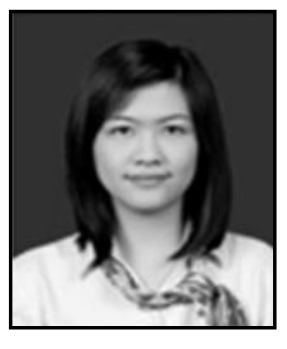

\section{Findra Kartika Sari Dewi}

was born in Purwodadi, Central Java in 1985. She got her Bachelor Degree in 2006 from University of Atma Jaya Yogyakarta majoring in Information System, and Master Degree in 2007 from the same university majoring in Information System and Financial Management.

Currently, she teachs Database and Programming in University of Atma Jaya Yogyakarta, Indonesia. Her current research interests are in data structure and data mining. 


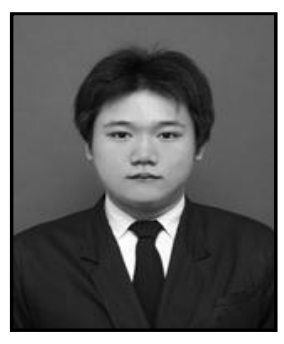

\section{Thomas Adi Purnomo Sidhi}

Was born in Temanggung, Central Java in 1986. He got the Bachelor Degree from University of Atma Jaya Yogyakarta majoring in Mobile Computing, and Master Degree from the same university majoring in Enterprise Information System.

Curently, He teachs Advance Web Programing, and Mobile Application Development in University of Atma Jaya Yogyakarta, Indonesia. His current research interest are in decision suport system and data mining. 
International Journal of Advanced Science and Technology Vol.62, (2014) 